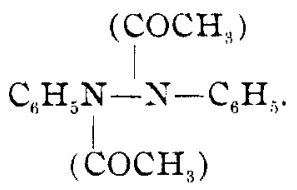

The diacetyl, dibenzoyl, and dinitroso derivatives' of dibenzy1hydrazine have been prepared. Also the dibenzoyl derivative ${ }^{\mathrm{r}}$ of 4 -methyldibenzylhydrazine and the diacetyl derivative' of $2,4^{-}$ dimethyldibenzylhydrazine.

None of the corresponding diderivatives of 2,4,5-trimethyldibenzylhydrazine have been prepared. In every trial a monoderivative of 2,4,5-trimethylbenzal-2,4,5-trimethylbenzylhydrazone was formed. It is assumed that the symmetrical hydrazine was oxidized to the hydrazone according to the equation

$$
\begin{gathered}
\left(\mathrm{CH}_{3}\right)_{3} \mathrm{C}_{6} \mathrm{H}_{2} \mathrm{CH}_{2} \mathrm{NHN} \mathrm{H}_{2} \mathrm{C}_{\mathrm{H}} \mathrm{C}_{6} \mathrm{H}_{2}\left(\mathrm{CH}_{3}\right)_{3}= \\
+\mathrm{O} \\
\left(\mathrm{CH}_{3}\right)_{3} \mathrm{C}_{6} \mathrm{H}_{2} \mathrm{CH}_{2} \mathrm{NHNCHC}_{6} \mathrm{H}_{2}\left(\mathrm{CH}_{3}\right)_{3}+\mathrm{H}_{2} \mathrm{O},
\end{gathered}
$$
and that then a hydrogen atom of the imide group was replaced by one of the substituting radicals.

\title{
THE PRECIPITATION OF COLLOIDS BY ELECTROLYTES
}

\author{
BY W, R. WhItNey aNd J. E. OHER.
}

Received Ausust 23, 100r.

\section{PART I.}

REVIEW OF THE WORK OF PREVIOUS INVESTIGATORS.

TH

$\mathrm{HE}$ purpose of this article is to call attention to the present condition of our knowledge concerning colloids by coordinating some of the facts and conceptions which have resulted from the work of various investigators in this field, and to append thereto a contribution to the subject, the result of recent experiments of our own together with a fairly complete index to the literature. It is hoped that the significance of this subject and its probable importance in connection with biological chemistry in its widest significance, as well as its claim to general chemical interest, may be brought more fully to the attention of chemists.

Any discussion of the subject which considers its history must begin with a reference to the work of Graham. He distinguished

${ }^{1}$ J.prakt. Chem., N. F., 62 ( 1900$)$. 
a new class of substances which exhibit little or no chemical affinity, which do not crystallize, which dissolve in various solvents apparently without any limiting solubility therein, which exhibit little or no tendency to diffuse when in solution, and which may be filtered from their solutions by animal membranes or parchment. These substances also exhibit the property of gelatinization or coagulation, the change often being spontaneous or brought about or catalyzed simply by the presence of acids, salts, etc. Graham gave the name colloid to this class of substances and called their solutions in water, alcohol, etc., hydrosols, alcosols, etc., while the names hydrogel, alcogel, etc., were given to the coagulum. He recognized that both organic and inorganic substances existed in these forms, and there were thus classified together such chemically different materials as silicic acid, ferric hydroxide, and gelatine.

The application by van't Hoff of the laws of gases to dissolved substances, together with Arrhenius' theory of dissociation, has shown us the probable molecular condition of many substances in solution. It has thus become often only necessary to determine the electrical conductivity of a solution, its freezingor boiling-point, its vapor-pressure, or one of a number of other properties, to learn whether the solute is present as simple molecules, or as polymerized or dissociated molecules. The extent of this association or dissociation may also be calculated.

A large part of the recent literature on the subject of colloids is concerned with attempts to learn the condition of the dissolved substance by some of the methods referred to. This work may be briefly summarized by stating that in most cases the conditions under which the measurements were made only left open the alternative conclusions that there was no substance in solution in the sense that ordinary acids, bases and salts and many simple organic substances dissolve, or the dissolved substance was possessed of an exceedingly high molecular weight corresponding to an association or polymerization not easily understood.

Thus Sabanejew (30) ${ }^{1}$ by means of freezing-point determinations is forced to attribute a molecular weight of over 100,000 to silicic acid in the hydrosol, while experiments by Gladstone and Hibbert (27) similarly lead to the conclusion that the molecular weights of ferric hydroxide and aluminum hydroxide in solution

1 Such figures refer to the references at the end of this article. 
exceed 5,000. It may be true that molecules of such magnitude exist in solution and that to them may be ascribed all the functions of simple dissolved molecules, but in the absence of proof that such is the case it will probably be more fruitful to follow the plan of several modern investigators ( $116,49,35$,), and consider the colloid solutions as simple suspensions of otherwise insoluble material. With this in view the first step is naturally to compare so-called colloidal solutions with what are known to be simple suspensions or heterogeneous mixtures. If a hydrosol resembles a mixture of sand and water in which the sand, because of its degree of fineness, does not settle, then the two ought to have other common properties. Such is actually the case, and it may be truly said that the hydrosols possess only those properties which would naturally be ascribed to them if they were regarded as suspensions of finely divided insoluble substances.

It would be impracticable here to consider in detail the hundreds of different colloids thus far studied, but a cursory view of the methods of their production will call attention to the following general principle: when any substance is produced within a liquid in which it is insoluble, it will, at least temporarily, exist there in the so-called colloidal state; but this colloidal state is rapidly destroyed by the presence of electrolytes.

A clearer idea of the value of what follows will be gained if one recognizes at this point the probable necessity of attributing electrostatic charges to particles of any kind when suspended in a liquid, and of assuming that these charges, while they may be positive or negative for different kinds of suspended matter, must still be of the same sign for all particles of the same substance. It is known that two different substances in contact assume equal and opposite electrostatic charges at their contact surfaces, and the work of Quincke, Coehn, and others has brought to light the regularities of this phenomenon.

Suspended particles of finely divided sulphur, silica, etc., in water, exhibit negative charges exactly as larger masses of the same substance in contact with water do, and when the suspension is placed between two electrodes connected with a source of electromotive force, the particles all migrate in the direction of the negative current. Conversely too, water in capillary tubes made of such materials as charge themselves negatively in contact with it, moves with the positive electricity through the capillary 
under the influence of the electric current. Similarly, particles suspended in turpentine assume in most cases the opposite charge as compared with the water, and under influence of the electric current move in the opposite direction.

Coehn (99) was led to conclude that a substance having a higher dielectric constant than the liquid in which it is suspended assumes the positive charge, while if of lower dielectric constant its charge is negative. It is probable that this does not alone determine the nature of the charge, which at least in many cases must depend also on electrolytic solution pressure and the partition coefficient for the ions of dissolved electrolyte between the suspended material and the liquid ( 123 ).

We seem forced then to recognize electrostatic charges on suspended particles, and it seems just as necessary to accept the conclusion that, as a result of these charges, suspended particles, whose masses are small enough, are equally distributed throughout the liquid and prevented from ever coalescing or settling because of the mutual repulsion of these charges. This mutual repulsion might also cause measurable osmose and corresponding osmotic pressure, properties which the colloids have to a slight degree.

The following illustrates some of the relations between "sols" and suspensions, the various methods of producing colloidal solutions or hydrosols, and the fact that absence of electrolytes usually insures permanency of colloidal state.

If an aqrieous solution of a silicate be treated with the equivalent quantity of an acid, free silicic acid and a salt are formed. This silicic acid is in the colloidal state, not in the form of a simple dissolved substance, and if the salt present is not very dilute, the acid becomes coagulated or exhibits its insolubility; $i . \ell$., the particles of suspended acid collect together. If the electrolyte be removed by osmose or otherwise, or if the silicic acid be made by such a method that electroly tes do not remain in the solution, the hydrosol is stable. It may, however, be precipitated at any time by the addition of electrolytes. For example, stable silicic acid hydrosol may be made by treating silicon tetraethyl with water, the alcohol resulting not having any effect on the silicic acid. This remains in the "sol" condition indefinitely but is precipitated by any electrolyte (Grimaux 15). Bredig (83) has shown that a great many metals may be produced in the hydrosol state by simply 
forming an electric arc under water between terminals of the metal desired. The heat of the arc volatilizes the metal and the vapors condense in the water, yielding deeply colored suspensions or colloidal solutions which often do not settle in measurable time, but which are immediately precipitated by even traces; of most electrolytes and are not affected by now-electrolytes.

If arsenic or antimony sulphide be produced by the action of hydrogen sulphide on aqueotis solutions of the oxides of these metals, there is at no time any considerable concentration of electrolytes present and there always results a deeply colored liquid, from which nothing is separated by ordinary filtration. Linder and Picton have studied these hydrosols and have shown that very low concentration of electrolytes completely precipitate them. Most other insoluble sulphides have been produced in the hydrosol state and have shown the same properties (Winnsinger 26).

Sulphur in the hydrosol state may also be produced by the mutual action of aqueous solutions of sulphur dioxide and hydrogen sulphide. The stulphur thus formed in the absence of electrolytes is in a stable, apparently soluble condition, from which it is precipitated by the presence of electrolytes (Stingl and Morawsky 1 2 ). Selenium also undergoes the same modification by analogous treatment (Schulze I9).

The hydroxides of many of the metals may be made as hydrosols by methods which involve the principle above stated. A solution of ferric hydroxide in aqueous ferric chloride solution. when subjected to osmose to remove most of the chloride, yields a colloidal hydroxide solution which is stable, but is precipitated by most electrolytes. Grimaux (I6) has shown that by the reaction between ferric ethylate and an excess of water, stable ferric hydroxide hydrosol is produced. Here there are no electrolytes present like those which, in the usual metathetical reaction for the production of such compounds, cause a coagulation and precipitation of the insoluble substance. Other hydroxide hydrosols may be made in a similar manner.

A solution of one part of egg albumen in ten or more parts of pure water does not yield any visible insoluble matter on boiling, although the effect of the heat may well have produced the insoluble material which more concentrated albumen solution would yield when similarly treated. This solution of so-called 
modified or alkali albumen is capable of coagulation or precipitation by electrolytes, although it is stable in their absence (Hardy I3I, I32).

Several purely organic colloids have been synthetically produced by Grimaux (16) and by Pickering (69), but always in the absence of electrolytes; moreover electrolytes easily precipitate or coagulate them, while non-electrolytes do not. There are produced in nature, in growing plant and animal cells, many colloids which probably owe their precipitation or deposition to electrolytes; this fact makes the study of the properties of this class of bodies of the utmost importance to biology.

In the case of simple, well recognized suspensions of insoluble material, such as silica, clay, oil, etc., it has long been recognized that the settling or coagulation is produced or very greatly accelerated by electrolytes, while non-electrolytes have little or no effect. This principle is used in connection with stamp-mills, etc., for the precipitation of so-called slimes, and it is of interest to the geologist in that it accounts for the formation of the delta at a river's mouth, where the settling seems to be induced by salt water rather than by loss of current in the stream. It is a principle also applied in the purification of water supplies and sewage. It has been studied by Scheerer (3), Barus and Schneider (35), Spring (I 39 ), Stark (I 4 ), and many others.

In general, acids and the salts of heavy metals are most active in this coagulative effect on suspensions, the alkali salts having the power to a less marked degree, but the general property of electrolytes of precipitating such suspensions, even when the former is exceedingly dilute, is repeatedly discovered. Similarly, as shown in the methods of preparation, the hydrosols or colloidal solutions are capable of coagulation or precipitation by electrolytes and often by exceedingly minute quantities. The colloidal platinum described by Bredig (83) is often precipitated in a few hours by the impurities in ordinary distilled water, while in very pure water it is stable for months or years. Quantitative work on this precipitation will be described later. It may be said here, however, that in this respect there seems to be really no difference between ordinary suspensions and so-called hydrosols. The two classes, if indeed they are not identical, also have the common property of very slight diffusibility and of behaving alike when filtered through porous cells ( 133 ), parchment membranes, etc., 
and they practically, without exception, exhibit in a pencil of light the Tyndall phenomenon of diffusion of the ray. Its path through the liquid is visible and the reflected light of the ray is polarized.

Several investigators, among them Linder and Picton (80), Coehn (79), Spring (I I2), and Hardy (I II), have shown that the colloidal material, in the hydrosol or so-called dissolved condition, migrates under the influence of the electric current and collects about one electrode, the direction of movement depending on the nature of the colloid. This is exactly what Quincke (5) and others have observed for visible particles in suspension under the same conditions.

Thus it seems most logical to consider so-called colloidal solutions as finely divided suspensions, the particles of which are much larger than simple molecules, the mixture being heterogeneous, instead of homogeneous, or consisting of two phases instead of one. This point has been very recently briefly discussed and a theory proposed by Donnan ( ${ }^{47}$ ).

A number of investigators (Schulze, Linder and Picton, Hardy) have studied quantitatively the precipitation of the colloids by electrolytes, and very interesting results have been obtained. At least in the case of many of the colloids, the molecular concentration of the acid or salt required to produce coagulation is determined almost wholly by the valence of the positive ion, being independent of the nature of the negative ion and having nearly the same value for different positive ions of the same valence. The reciprocal of this concentration is designated the coagulating power of the electrolyte; and if its value for positive univalent ions be represented by $\mathrm{I}$, that of the bivalent ions becomes about 30 and that of the trivalent about 1000 . Quantitative experiments by four different chemists on the sulphides of arsenic, antimony, and cadminm, on the hydroxide of manganese, and on boiled dilute egg albumen, have shown the above ratio to hold fairly well. This point may well be illustrated by examples: Colloidal antimony sulphide is precipitated by most of the univalent salts when the concentration is about I part by weight of salt to 200 parts of the solution; for the bivalent salts, this value is about I part by weight to 2,000 of water, while with the trivalent ions, I part of the salt to 30,000 or 40,000 of water is sufficient. Corresponding concentrations 
of non-electrolytes are practically without effect. Another author states that sodium, potassium, and ammonium salts precipitate colloidal copper sulphide when I part by weight of the salt is present in from 60 to 400 parts by weight of water. Salts of the bivalent elements, when present, I part in from 3,000 to 7,000 parts of water and the trivalent salts in from 30,000 to 70,000 parts of water. Undissociated acids are without effect, while dissociated acids are about like univalent salts. For a certain arsenious sulphide solution, I part of potassium chloride to I 37 parts of water is necessary; while with ferrous sulphate and similar salts, I part in 2000 or 3000 parts of water, and with ferric chloride I part in 50,000 parts of water suffices, the values for iron, chromium and aluminum in this case being 50,000, 83,000 and 20,000. As might be expected, the alums here act as trivalent-metal salts, while the ferrocyanide and ferricyanide of potassium act like other valent-metal salts. Experiments on suspended sulphur by one author, and on diluted, boiled egg albumen by another, have shown the same quantitative relations.

Several chemists have suggested possible explanations of these phenomena. It is thought by some recent investigators that the coagulating power of salts on aqueous suspensions and on many of the so-called colloids, is attributable to the positive or to the negative ion of the salt, depending on whether the suspended particles themselves are negatively or positively charged with respect to the solution; that is, that the negatively charged suspensions are precipitated by positively charged ions, and conversely. Spring (I39) believes the statical charge, which it is assumed the ions of electrolytes carry, neutralizes the statical charges of opposite sign on colloidal particles, and cites cases which seem to support the belief. For example, he states that certain colloids are negative and therefore require for their immediate precipitation or coagulation a certain concentration of a positive ion. Solutions of various salts of the same cathion should therefore be equally active as precipitants when they are equivalent in concentration, while equivalent solutions of salts of the same anion should not be equally active. This he has shown to be the case. Whetham (I2I) has attempted to explain the observed relative coagulating or precipitating powers of ions is influenced by their valences as follows. He assumes that it is necessary that a certain 
minimum electric charge, carried by the ions, must be brought within reach of the colloidal group with a certain minimum frequency throughout the solution in order to produce coagulation. Eridently equal charges should be available from $2 n$ triad ions, $3^{n}$ diads and $6 n$ monads, where $n$ is a whole number. Probability of contact between colloid and ion should be proportional to the concentration $C$ of the ion or equal to $A C$, where $A$ is a constant. The probability of two such ions being together is $\overline{A C}^{2}$ and of " $n$ " ions $\overline{A C}^{-1}$. For equal coagulative power of ions of different valences $\overline{A C}_{3}^{2 n}=\overline{A C}_{2}^{3 n}=\overline{A C}_{1}^{6 n}=B$ (a constant). The concentration of trivalent, bivalent and univalent ions respectively being $C_{3}, C_{2}, C_{1}$, hence $C_{1}: C_{2}: C_{3}=1: B^{\frac{1}{n}}: B^{\frac{1}{3} n}=1: K^{2}: K^{-2}$, where $K$ is a constant. That is, from the known coagulating powers of univalent and bivalent ions, that of ions of higher valencies could be calculated. The calculated and observed values for trivalent ions thus far investigated agree very satisfactorily. Measurements with quadrivalent ions have not been made.

Whetham supposes a certain minimum charge has to be brought into contact with the colloid particles with a certain minimum frequency throughout the solution. We see no reason for assuming a certain minimum frequency. On the contrary it is more probable that whenever contact between any colloid particle and a certain necessary minimum amount of electric charge takes place, coagulation of that particle results, and that the frequency of contact simply determines the rapidity of coagulation of the solution as a whole. Evidently then, we might have various concentrations of the same electrolyte, all of which precipitated the colloid completely, but after expiration of different times. This velocity would then be a function of the concentration and for immediate precipitation the relationships might hold, as shown by Whetham. It is a well-known fact that with all the colloids the velocity of coagulation or precipitation may assume any desired magnitude depending on the concentration of precipitating agent. The many comparisons of the coagulating power of different electrolytes for immediate coagulation led to the discovery probably first stated by Schulze, but confirmed by Linder and Picton and others, that ions of the same valence have only approximately the same precipitating or coagulating power, while for different valence the 
power is greatly different as stated above. Spring has added the velocity of migration of the ion as a factor in determining its precipitating power because of the fact observed by him that potassium, sodium, and hydrogen in this respect stand in the order of their migration rates. Such a dependence is to be expected if the assumption of Whetham is a correct one. In this connection it is interesting to note that Linder and Picton have observed, apparently, a peculiar class of analogous phenomena in the case of colloidal aniline colors. They mixed solutions of aniline colors which migrate in opposite direction under the influence of the current and whose particles under our present hypothesis are possessed of opposite electric charges, and report that "in general there is a tendency to aggregation between such substances." The mixed solution was either completely precipitated or the particles simply increased in size; just such effects as are produced by electrolytes in large and small quantities respectively. Thus, aniline blue $(-)$ and methyl violet $(+) \mathrm{mix}$ in this way, and, unless very dilute, precipitate; and even when dilute, optical tests show that the particles have increased in size. Aniline blue $(-)$ and magdala red $(+)$ give similar results. In dilute solutions, to show that some union had taken place, the authors filtered the mixture through a porous cell, which held back both in case of the mixture, while aniline blue would filter through when tested separately. Rosaniline hydrochloride and aniline blue acted similarly. Here, as Linder and Picton state, we have what appears to be "a mimicry of the ionic dissociation," but is there any reason why it may not be a true conception of the actually occurring phenomena?

Finally, it must be mentioned that Linder and Picton have stated that when a colloidal solution, or, as they designate it, a pseudo solution, of arsenious sulphide, is precipitated by a salt such as barium chloride, a small portion of the barium is precipitated along with the sulphide, while the corresponding quantity of the negative element, chlorine, is not, and that this barium cannot be removed from the precipitate by washing with water. It can, however, be replaced by another positive ion by washing with a solution of an appropriate salt. 


\section{PART II. \\ EXPERIMENTS ON THE CO-PRECIPITATION OF THE ELECTROLYTE WITH THE COLLOID.}

The results of Linder and Picton, which have just been referred to, seemed to us to open a field of great scientific interest, and one likely to become of much practical importance to the analyst, in connection with the carrying down and retaining of otherwise soluble materials by precipitates. In order to confirm and extend these results, our investigation was undertaken. A colloidal arsenious sulphide solution was made by pouring a solution of Merck's C. P. arsenious oxide, a little at a time, into an excess of a saturated aqueous solution of hydrogen sulphide, so that the resulting solution contained about I per cent. arsenious sulphide. The excess of hydrogen sulphide was then removed by passing washed hydrogen through the mixture. There resulted a deep lemon-yellow solution which was opaque by reflected light but transparent by transmitted light, and which, except for a practically unweighable quantity of precipitated sulphide, passed readily through the best filter-paper. It also showed no signs of heterogeneity under the microscope. The water used in these experiments was twice distilled, the second time from alkaline permanganate solution, and was such as is usually employed in electrical conductivity measurements. An approximately i per cent. solution of barium chloride was made by dissolving the crystallized salt in water. Thirty cc. of this solution were added to $200 \mathrm{cc}$. of the colloidal solution, which produced immediate and complete precipitation of the arsenious sulphide. This was filtered and carefully washed until the washings gave no test for chlorine with silver nitrate. The barium in the filtrate and wash-water was then precipitated as sulphate and weighed, and at the same time a determination of the barium in $30 \mathrm{cc}$. of the original barium chloride solution used was likewise made. The weights of sulphate obtained were 0.2590 and 0.2849 gram respectively, which corres pond to 0.1523 and 0.1675 gram of barium; or a loss of 0.0152 gram of barium which was held by the precipitated sulphide. The analysis of the filtrate from the arsenious sulphide precipitate for chlorine by weighing silver chloride showed 0.0863 gram as compared with $0.0865 \mathrm{gram}$ found in the same way in $30 \mathrm{cc}$. of the baritun chloride solution used. 
This shows that the chlorine was not carried down with the sulphide to a measurable extent.

To determine the effect of concentration of the colloid on this phenomenon, half as much, or roo cc., was taken and diluted to $200 \mathrm{cc}$, the volume used above. Thirty cubic centimeters of the barium chloride solution as before were added to this and the analysis made as above. It was found that $0.0078 \mathrm{gram}$ of barium had been carried down by the sulphide. Finally $100 \mathrm{cc}$. of the colloid solution, $80 \mathrm{cc}$. of water, and $50 \mathrm{cc}$. of the barium chloride were mixed and the process carried out as before. The barium held by the sulphide was here 0.0075 gram. As these are practically half of the previous quantity (o.o152), it is evident that the composition of the precipitated colloid is independent both of its own concentration in the solution and of that of the barium ions. The approximate relationship in the precipitate is represented by the symbol $g \circ\left(\mathrm{As}_{2} \mathrm{~S}_{3}\right): \mathrm{Ba}$. It is doubtless true that the barium exists here as hydroxide as will be shown below. That the barium remained adhering to the sulphide, was shown by the following experiment, which is a repetition of Linder and Picton's procedure. $100 \mathrm{cc}$. of the colloid solution were diluted with 100 cc. of water and coagulated with $30 \mathrm{cc}$. of the barium chloride solution. The precipitate was washed free from chloride and then allowed to stand in dilute ammonium chloride solution for two days. The precipitate was again filtered and the barium in the ammonium chloride solution determined as sulphate. Thus $0.007 \mathrm{r}$ gram of barium was found, which was 93 per cent. of that carried down by the sulphide ( $0.0076 \mathrm{gram})$. This had been removed from the washed sulphide by the ammonium chloride solution. This is in accord with Linder and Picton's statement that the metal carried down by the arsenious sulphide can be replaced by other metals by digesting as above.

The natural assumption to make in the light of these experiments is that the colloid causes hydrolysis of the salt and that while the base is carried down in the precipitate, the filtrate contains the free acid. How this precipitation of a basic hydroxide can be produced, together with the liberation of the acid, is yet to be explained. That the filtrate in the above experiments did contain free acid after the process, while it did not before, was readily shown, and the quantity which was found by titration with alkali agreed with the assumption. For example, 
in cases where, as above, 200 and Ioo cc. of the colloid had been used, the free acid in the filtrate was found to be equivalent to $0.008 \mathrm{I}$ and 0.0038 gram of chlorine respectively. The very dilute solutions made the determination difficult; but these values correspond quite well with the results in the case of the barium carried down which require 0.0079 and 0.0039 gram respectively. Therefore, equivalent quantities of barium and hydroxyl are precipitated with the colloid.

This power of what one might consider chemically inert material, by virtue of which it decomposes neutral salts in the presence of water and combines with or holds either the acid or base, has already been discovered in the case of solid substances, especially porous material such as bone-black, silica, precipitated colloids, and has received very interesting treatment by Van Bemmelen ( I $^{\mathrm{I}}$ ). In the case of solids, however, quantitative measurements seem hardly destined to lead to such interesting results as are promised by a study of what appears to be the same phenomenon in colloidal solutions.

The experiments above described have been repeated, using strontium, calcium, and potassium chlorides instead of barium chloride, and the following results which are tabulated below, together with those given above, were obtained. The calcium was precipitated as oxalate and weighed as oxide. The strontium was weighed as carbonate and the potassium as potassium platinichloride. In the first collumn is given the amount of the colloidal solution used, in the second the quantity of water added, in the third the volume of the precipitant used, in the fourth the weight of the metal in the precipitant used, in the fifth the weight of this metal carried down by the precipitate, in the sixth the weight of chlorine found in the filtrate as free acid, and in the seventh the weight of chlorine corresponding to the metal in the fifth column.

\begin{tabular}{|c|c|c|c|c|c|c|}
\hline $\begin{array}{l}\text { Colloid } \\
\text { solution. } \\
\text { cc. }\end{array}$ & $\begin{array}{c}\text { Water. } \\
\text { cc. }\end{array}$ & $\begin{array}{c}\text { Precipitant. } \\
\text { cc. }\end{array}$ & $\begin{array}{l}\text { ALCILM } \\
\text { Metal in } \\
\text { solution. } \\
\text { Gram. }\end{array}$ & $\begin{array}{l}\text { MORIDL. } \\
\text { Metal in } \\
\text { precipitate. } \\
\text { Gram. }\end{array}$ & $\begin{array}{c}\text { Chlorine as } \\
\text { ftee acid. } \\
\text { Gram. }\end{array}$ & $\begin{array}{l}\text { Chlorine } \\
\text { calculated } \\
\text { from metal. } \\
\text { Gram. }\end{array}$ \\
\hline IOO & 100 & 25 & 0.0724 & 0.0020 & 0.0036 & 0.0036 \\
\hline 200 & $\ldots$ & 25 & 0.0724 & 0.0038 & 0.0073 & 0.0067 \\
\hline 100 & 100 & 25 & 0.0724 & $\ldots$ & $0.004:$ & 0.0036 \\
\hline \multicolumn{7}{|c|}{ STRONTIUM CHLORIDE. } \\
\hline 200 & $\cdots$ & 25 & 0.1071 & 0.0072 & $\ldots$ & $\cdots$ \\
\hline 200 & $\ldots$ & 25 & $0.107 \mathrm{I}$ & $0.008_{3}$ & $\ldots$ & $\cdots$ \\
\hline 100 & 100 & 25 & O.IO $7 \mathrm{I}$ & $\cdots$ & 0.0040 & $\cdots$ \\
\hline
\end{tabular}




\begin{tabular}{|c|c|c|c|c|c|c|}
\hline $\begin{array}{l}\text { Colloid } \\
\text { solution, } \\
\text { cc. }\end{array}$ & $\begin{array}{c}\text { Water. } \\
\text { cc. }\end{array}$ & $\begin{array}{c}\text { Preciptant. } \\
\text { cc. }\end{array}$ & $\begin{array}{l}\text { ARIUM } \\
\text { Metal in } \\
\text { solution. } \\
\text { Gram. }\end{array}$ & $\begin{array}{c}\text { HLORIDE. } \\
\text { Metal in } \\
\text { precipitate. } \\
\text { Gram. }\end{array}$ & $\begin{array}{c}\text { Chlorine as } \\
\text { free acid. } \\
\text { Gram. }\end{array}$ & $\begin{array}{l}\text { Chlorine } \\
\text { calculated } \\
\text { from metal } \\
\text { Gram. }\end{array}$ \\
\hline 200 & $\ldots$ & 30 & o. 1675 & 0.0152 & $0.008 \mathrm{I}$ & 0.0079 \\
\hline 100 & 100 & 30 & 0.1675 & $0.007^{8}$ & 0.0038 & 0.0039 \\
\hline 100 & 80 & 50 & $0.279 \mathrm{I}$ & 0.0075 & $\cdots$ & $\cdots$ \\
\hline \multicolumn{7}{|c|}{ POTASSIUM CHLORIDE. } \\
\hline 100 & $\ldots$ & . & 2.0 & 0.0032 & 0.0030 & 0.0029 \\
\hline 200 & $\ldots$ & $\cdots$ & 5.0 & $\ldots$ & 0.0073 & $\ldots$ \\
\hline
\end{tabular}

The quantities of these various metals carried down by Ioo cc. of the colloid are calculated and collected in the following table. The third column contains the quantities of the respective elements chemically equivalent to the barium absorbed. This element is chosen on which to base a comparison, because its quantitative determination is probably the most accurate.

I.

$\mathrm{Ca}$
$\mathrm{Sr}$
$\mathrm{Ba}$
$\mathrm{K}$

II.

Grams observed.

$$
\begin{array}{r}
\left\{\begin{array}{l}
0.0019 \\
0.0020
\end{array}\right. \\
\begin{array}{l}
0.0036 \\
0.0041
\end{array} \\
0.0076 \\
0.0036
\end{array}
$$

III.

Grams calculated.

$$
\begin{aligned}
& 0.0022 \\
& 0.0049 \\
& 0.0076
\end{aligned}
$$$$
0.0043
$$

In the case of another solution of the colloid which contained Ig grams of arsenic trisulphide per liter, the following results were obtained:

$\begin{array}{cccc}\begin{array}{c}\text { Colloid } \\ \text { solution. } \\ \text { cc. }\end{array} & \begin{array}{c}\text { 25 cc. chlo- } \\ \text { ride solution, }\end{array} & \begin{array}{c}\text { Metal in } \\ \text { solution. } \\ \text { Gratn. }\end{array} & \begin{array}{c}\text { Chlorine } \\ \text { as acid. } \\ \text { Gram. }\end{array} \\ 50 & \mathrm{Ba} & 0.1394 & 0.0019 \\ 50 & \mathrm{Ba} & 0.1394 & 0.002 \mathrm{I} \\ 50 & \mathrm{Ca} & 0.0706 & \ldots \ldots . \\ 50 & \mathrm{Ca} & 0.0706 & \ldots .0017 \\ 50 & \mathrm{Ca} & 0.0706 & 0.002 \mathrm{I} \\ 50 & \mathrm{Sr} & 0.1071 & 0.002 \mathrm{I} \\ 50 & \mathrm{~K} & 2.00 & 0.0039 \\ 100 & \mathrm{Ba} & 0.1394 & 0.0039 \\ 100 & \mathrm{Ba} & 0.1394 & 0.0042 \\ 100 & \mathrm{Sr} & 0.107 \mathrm{I} & 0.004 \mathrm{I} \\ \text { I00 } & \mathrm{Ca} & 0.0706 & 0.0040 \\ 100 & \mathrm{Ca} & 0.0706 & 0.0038 \\ 100 & \mathrm{~K} & 2.00 & \end{array}$

The determinations of the quantity of metal carried down by the precipitate were not made in these experiments as the time at our disposal would not permit it. The analysis of the filtrate for fere acid was considered a measure of the quantity of metal car- 
ried down by the precipitate as it proved itself to be in the pre. rious experiments where both were determined.

Therefore, since the quantities of free acid were found to be the same, within the limits of error, in all the experiments, it is erident that equivalent quantities of the four metals were precipitated with the colloid. Thus, not only does this colloid, when precipitated, bring about a hydrolysis of the salts, absorb the base, and liberate the acid, but, what is equally striking, it carries down with itself chemically equivalent quantities of the different bases. In other words, into this precipitated colloid, barium, strontium, calcium, and potassium enter in the proportions of their equivalent weights. It is evident that this result supports the liypothesis of Whetham (see above).

\section{PART III.}

AN INDEX TO THE IITERATURE OF COLLOIDS.

The accompanying list of references is a fairly complete one and includes some articles which are only indirectly connected with the subject. To facilitate its use, the matter treated in the article is briefly stated, we having taken the liberty of substituting in many cases descriptive clauses for the titles given the papers by the respective authors. Owing to the necessary brevity of these modified descriptions, much very important material contained in many of the articles is still not specially referred to, but it was thought that even these brief descriptions might facilitate the use of this collected literature.

\section{REFFRENCES TO COLIOIDS.}

I. Graham: "Chemical and Physical Researches." Colloidal substances and nomenclature.

2. Bunge: "Lehrbuch der physiologische Chemie." Assumes albumens to be suspensions and not solutions.

3. Scheerer: Pogg. Ann., 82, 4I9-429 (I85I). Coagulation or precipitation of slimes by electrolytes.

4. Crum : Ann. chim. phys., 89, I56 (1854). Acid necessary to precipitate colloid $\mathrm{Al}_{2} \mathrm{O}_{3}$ is absorbed by the precipitate. The same true of alkalies in case of colloidal metastannic acid.

5. Quincke : Pogg. Ann., II3, 5I3 (I86I). Motion of solid particles suspended in liquids when under influence of electric current.

6. Reitlinger and Kraus : Wiener Ber., 46, 376 (1863). Motion of suspended particles in water when under infiuence of electricity.

7. Lommel : Pogg. Ann., I31, I05 (1867). The scattering of light by sinall particles. 
8. Warington : J.prakt. Chem., I04, 316 (1868). Absorption of acids and bases from neutral salt solutions by precipitated hydrates of aluminum and iron.

9. Shloessing: Compt. rend., 70, I345 (1870). The coagulation of slimes by dilute salt solutions.

ro. John Strutt : Phil. Mag., 4I, 270, 447 (187I). The scattering of light by small particles.

II. Holtz: Pogg. Ann., 7, 490 (I876). Motion in water of suspended particles under influence of electric current.

12. Stingl and Morawasky : J. prakt. Chem., 20, 76 ( 1879 ). Coagulation of colloidal sulphur by electrolytes.

13. Schulze : $J$. prakt. Chem., 25, 431 ( I882). Coagulation of colloidal arsenious sulphide by electrolytes.

14. Schulze: $J$. prakt. Chem., 27, 320 ( 1883 ). Coaguiation of colloidal antimony sulphide by electrolytes.

15. Grimaux : Compt. rend., 98, IO5, 23I (I884). Preparation of colloidal ferric hydroxide from ferric chloride and sodium ethylate. A new synthetic organic colloid and its coagulation by salt solutions.

16. Grimaux : Compt. rend., 98, 1434 (1884); Bull. Soc. Chim., 44, 21. Colloidal ammonia-cupric oxide solution. New method for production of colloidal silica solution, also new synthetic organic colloid. All are coagulated by electrolytes.

I7. Grimaux : Compt. rend., 98, I578 (1884). A theory of coagulation of colloidal solutions.

I8. Wiedemann and Ludeking: Ann. Phys. Chem., 25, I45 (1885). Hydration, solution, and coagulation of organic colloids and the corresponding heat effects.

I9. Schulze: J. prakt. Chem., 32, 390 (1885). Colloidal selenium and tungsten solutions.

20. Thoulet: Compt. rend., 100, I002 (1885). Absorption by insoluble powders of salts from aqueous solutions.

21. Carl Barus : Bull. U. S. Geol. Survey, 36 (1886); Am. J. Sci., (3), 37, 122 (1889). Subsidence of fine solid particles in liquids.

22. Muthmann: Ber. d. chem. Ges., 20, $98_{3}$ (1887). Clear varicolored solutions of colloidal silver.

23. Spring and Boeck : Bull. Soc. Chim., 48, I65 (I887). Colloidal copper sulphide solution and its coagulation by various electrolytes. Ibid., 48, r7o ( 1887 ). Colloidal oxide of manganese solutions and the coagulation by electrolytes.

24. van Bemmelen : $J$. Chem. Soc. (London), 54, 985 (1888).

25. van Bemmelen: Rec. trav. chim. pays-bas, 7, 37 (1888). Equilibrium conditions between various colloidal substances as precipitates and their water-content.

26. Winnsinger : Bull. Acad. Roy. Belg., 15, 390 (1888). Account of preparation and coagulation by electrolytes of fifteen colloidal sulphide solutions.

27. Gladstone and Hibbert: Phil. Mag., 28, 38 (1889). Molecular weight of colloids in solution determined cryoscopically. 
28. Ljubawin: J. muss, chem. Ges., 21, 397 (I889). Changes in colloidal solutions produced by freezing.

29. Paterno: Ztschr. phys. Chem., 4, 457 (1889). Theoretical consideration of colloidal solutions.

30. Sabanejew: $J$. russ. chem. Ges., 21, 5I5 (1889). The molecular weight of many colloids in solution determined by the cryoscopic method.

31. Voigtlander: Ztschr. phys. Chem. 3, 316 (1889). The diffusion of substances in colloids.

32. De Jager: Archiv. Pathol. Anat.,(1890), pp. I21, 182, 187. Action of unorganized ferments.

33. De Jager: Centrbl. für die Medezin Wissensch I, 28, 49, 5 I (1890). Research on the action of unorganized ferments.

34. Sabanejew : J. russ, chem. Ges, 22, I02 (1890). Molecular weights of gallic and tannic acids in solutions.

35. Barus and Schneider: Ztschr. phys. Chem., 8, 278 (189I). Colloidal solutions considered as simple suspensions. Experiments on colloidal silver.

36. Carey Lea: Phil. Mag., 3I, 497 (I89r). Colloidal silver solutions : methods of preparation.

37. Carey Lea : Phil. Mag., 32, 337 (r891). Colloidal silver solutions : preparation and properties.

${ }_{3}$ S. Edkins : $J$. Physiol., 12, 193 (1891). Precipitation of casein by salts.

39. A. J. Prange: Ber. d. chem. Ges., Ref. 24, 69 (1891). Rec. traz'. chim. Pays-Bas, 9, I2I. An allotropic state of silver.

40. Ringer: $J$. Physiol., 12, I64 (1891). Coagulation of casein by calcium salts.

4r. Ringer: $J$. Physiol, 12, 378 (189I). Coagulation of egg albumen solutions by electrolytes and heat.

42. Sabanejew : J. russ. chem. Ges., p. 80 (189I). Effect of freezing the solvent from colloid solutions.

43. Sabauejew : Ber. d. chem. Ges., 24, 666 (I89I). Researches on a classification of soluble colloids.

44. Schneider: Ber. d. chem. Ges., 24, 224I (189I). Colloidal gold sulphide solution.

45. Ambronn: Chem. Centrbl., x, 369 (I892); Centrbl. für Phys., 5, 536-537. Freezing of colloidal solutions.

46. A. Kossel: Chem. Centrbl., I, I39 (1892). Deutsche Medezin Wochenschrift, I7, I297-I299. Slime and slime-forming materials.

47. Linebarger: $A m . J$. Sci, 43, 218 (I892). Colloidal tungstic acids : osmotic pressure. Ibid., 43,426. Osmotic pressure of gum arabic and dextrine solutions.

48. Linder and Picton: $J$. Chem. Soc. (London), 6r, I 50 ( 1892 ). Comparisons of various colloids in aqueous solutions. Their precipitation, Tyndall effect and migration under influence of electric current.

49. H. Picton: $J$. Chem. Soc. (London), 61, I37 (I892). The physical constitution of some sulphide solutions.

50. Ramsay: Chem. Centrbl., I, 5 I5 (1892); Proc. Chem. Soc. (London), 
8, 17; Chem. Nezes, 65, 90. Brownian movement in relation to colloidal solutions.

5I. Spring and Lucion: Ztschr, anorg. Chem, 2, I95 (1892). Effect of salts in solution on the dehydration of precipitated cupric hydroxide.

52. Tammann: Ztschr. phys. Chem., 18, 426 (1895). Reactions of unorganized ferments.

53. Bödlander : Göttinger, Nach., 7, 267 (1893). Coagulation of suspensions of clay by electrolytes.

54. Hoffman and Kruss : Ztschr. anorg. Chem, 3, 89 ( I893). Bone coal absorbs alkali and leaves acid when in contact with neutral salt solution.

55. Schneider: Ztschr. anorg. Chem., 3, 78 (1893). Alcosol of colloidal silver precipitated at critical temperature of alcohol.

56. Hugo Schiff: Chem. Centrbl., 2, 521 (1893); Chem. Ztg., 17, 1000. A modification of crystallizable salts.

57. Schneider : Chem. Centrbl., I, 382 ( 1893 ); Ztschr. anorg. Chem., 3, 78.

58. Carey Lea : Ztschr. anorg. Chem., 7, 34I (1894). A colloidal silver which does not show Tyndall effect.

59. O. Lehmann: Wied. $A n n,, 52,455$ (I894). A new phenomenon concerning the passage of electricity through a difficulty conducting liquid.

60. O. Lehmann : Ztschr. phys. Chem., 14, I57 (1894). Sedimentation and absorption of dyes.

6r. Schneider: Ztschr. anorg. Chem., 5,80 (1894). Colloidal purple of Cassius, coagulation by electrolytes.

62. Schneider: Ztschr, anorg. Chem, , , 339 (1894). Solubility of colloidal silver in organic liquids.

63. J. Sjoqoist: Scandinav. Archiv. für Physiol., 5, 277 (1894). Albumen solutions conduct electric current and the colloid may act as anion or cathion.

64. van Bemmelen: Ztschr. anorg. Chem., 5, 466 (I894). Dehydration of the hydrogel of cupric hydrate.

65. Bliss, W. J. A.: Phys. Rev., 2, 241, 273 (1895). Apparent force between particles permanently suspended in liquid as infiuenced by presence of electrolytes.

66. Barus, C. : Ztschr. phys. Chem., 16, 573 (1895). Colloidal silver so. 1utions.

67. Holleman : Rec. trav. chim. pays-bas., I4, $7 \mathrm{I}$ ( I895).

68. Maltezos : Compt. rend., I21, 303 (I895). The effect of the electro1 ytes on the Brownian movement.

69. Pickering : J. Physiol., 18, 54 (1895). Synthesized organic colloids coagulated by electrolytes. Physiological effect same as proteids.

70. Linder and Picton: $J$. Chem. Soc., 67, 63 (I895). Arsenious sulphide colloid absorbs metal of electrolyte on coagulation. Quantitative comparisons of precipitating powers of various electrolytes.

71. J. W. Pickering: Compt. rend., 120, I348 (1895). Synthetic colloids and coagulation.

72. Ringer: $J$. Physiol., 18, 425 (I895). Effects of calcium and sodium in coagulation of blood serum and casein, and on action of frog's heart. 
73. Schmidt: Ztschr. phys. Chem, I5, 56 (1895). Absorption of salts, etc., from solution by carbon.

74. Calvert and Ewan: Chem. News, 74, I2 I 1896). Colloidal chromosulphuric acid.

75. Delafontaine: Chem. News, 73, 284 (I896). Colloidal compounds of the rare metals.

76. Krafft: Ber. d. chem. Ges., 29, I334 (1896); 28, 2566, 2573; 32, 1584 , I623 (1899). Colloidal solutions of various soaps, theoretical considerations.

77. Martin : J. Physiol., 20, 364 (1896). Filtration of albumen and other colloids from solution by membranes held in earthenware filters under pressure.

78. van Bemmelen: Ztschr. anorg. Chen., I3, 233 (1896). Vapor-pressure of hydrated silicic acid.

79. Cohen : Ztschr. Elektrochem., 4, 63 (1897). Electrical migration of colloids in solution.

80. Linder and Picton: J. Chem. Soc. (London), 71, 568 (1897). Electrical migration of various colloids and aniline dyes. Its direction as dependent on the composition of the colloid.

8I. R. A. Young : $J$. Physiol., 22, 40I (I897). Coagulation of carbohylrates by salts in solution.

82. Barus, C: Am. J. Sci., 6, 285 (1898). Colloidal glass. Compressibility of colloids with the applications to the jelly theory of the ether.

83. Bredig, G: Ztschr. angew. Chem., 95I (1898). Colloidal metal solutions made by subaqueous arc. Precipitation by electrolytes.

84. Bugarozky and Liebermann: Archiv. Ges. Physiol., 72, 51 (1898). Consider albumens as solutions of electrolytes.

85. Caldecott: I. Chem. Metall. Soi, 82, 96 (1898). Coagulation of slimes by lime.

86. Coehn: Wied. Ann, 64, 217 (1898). Law of electrical excitation of insoluble matter suspended in liquids.

87. Crismer: Memoire in'so of l'Acad. Roy. Bel., 58, (1898). The mechanism of physical precipitations.

88. Carrick: J. Chem. Metall. Soc. 82, 96 (IS98). Coagulation or precipitation of slimes.

89. A. Heidweiller: Wied. Ann, 65, 535 (ISgS). The contact electricity between metals and liquids.

9o. Linebarger: J. Am. Chem. Soc, 20, 375 (1898). Velocity of coagulation of colloidal solutions.

9I. Lottermoser and Meyer: J. prakt. Chem., 57, 484 (1898). Production of colloidal mercury and mercury salt solutions.

92. Lottermoser and Meyer: J. prakt. Chem., 57, 540 (I898). Precipitation of colloidal silver solution.

93. Mijers: Rec.trav, chim. pays-bas, 17, r7t (1898). The nature and action of semipermeable membranes.

94. Prister: J. Chem. Metall. Soc., 82, 130 (1898). Coagulation of slimes. 
95. Spring, W.: Bull. de l'Acad. Roy. de Bel., 3, I35, 78 (1898). Influence of electricity on the coagulation of liquid suspensions.

96. van Bemmelen, J. M.: Ztschr, anorg. Chem., 18, 98 ( I898). Absorption power of different colloid jellies for water and the loss of this power under the influence of heat.

97. Williams, J. R.: J. Chem. Metall, Soc., 82, I15 (1898). The stability of slimes.

98. Zsigmondy: Ztschr. Elektrochem., 82, 546 (1898); Ann. Chem. (Liebig), 301, 36I. Colloidal gold and colloidal stannic acid, migration under influence of electric current.

99. Coehn : Wied. Ann., 64, 217 (1898), Electric charges.

Ioo. Duhen : J. phys. Chem, 4, 65, (1899). Heat of hydration of colloids.

ror. G. Bredig and R. Muller von Berneck: Ztschr, phys. Chem, 3r, 254 (1899). Inorganic ferments. Colloidal metal solutions produced by subaqueous arcs. Catalysis by colloidal metal solutions.

I02. Friedenthal : Chem. Centrbl., 924, ir6I (1899). Molecular weight of soluble starch by freezing-point method.

103. Friedenthal: Centrbl. für Phys., I3, 54, 58 (1899). Chemical combination between colloidal and crystalloidal substances.

104. Hardy : $\int$. Physiol., 24, 288 (1899). Coagulation of albumen solutions by electrolytes. Quantitative relations. The isoelectric point. Migration caused by electric current.

105. Hardy: $J$. Physiol., 24, 158 (1899). Structure of gelatinized colloids. Effect of electrolytes on coagulation. Biological significance.

I06. Krafft : Ber. d. chem. Ges., 32, $5_{5} 84$ ( 1899 ). Boiling of colloidal salt solutions. Conditions of the crystallization of colloidal salt solutions. Formation of membranes by colloidal salts in the dyeing process.

107. Lottermoser: J. prakt. Chem., 59, 489 (1899). Colloidal mercury, bismuth, silver, stannic acid, etc.

108. Carey L.ea: Am.J. Sci., p. 479 (1899); p. 483 (I89r). Preparation of colloidal silver.

109. Pauli : Archiv. Ges. Physiol., 78, 355 (1899). Coagulation of egg albumen solutions by salt solutions. Negative ions exert predominating intuence.

I Io. Spring: Rec. traa. chim. pays-bas, r8, I53 (I899). Optical clarity of solutions.

I I. Spring: Bull. Acad. Belg., 37, 300 (I899). Diffusion of light ray by colloids.

I1 2. Spring : Rec.trav. chim. pays-bas, 18, 233 (1899). The dispersion of light by salt solutions.

I13. Spring: Bull. Acad. Belg, 37,300 (1899). Tyndall effect in salt solutions.

1 14. Stark: Wied. Ann, 68, II7 (I899). Coagulation of colloidal solutions attributed to air.

I 5. Stark: Wied. Ann., 68,618 (I899). Suspensions and colloidal solutions and the bubbles of air formed on coagulation. 
I16. Stoeckl and Vanino: Ztschr, phys. Chem., 30, g8 (1899). Colloid solutions considered as simple suspensions.

117. van Bemmelen: Ztschr. anors. Chem., 20, 185 ts9g). Hydration of jellies.

I18. van Bemmelen: Ztschr. anory. Chem., 18, 98 (I899); 18, I4 (I899). The formation of, and absorption by, colloidal jellies.

II9. Vanino and Traubert: Ber. $d$. chem. Ges., 32, I072 (I899). Production of colloidal bismuth solution.

120. Whetham: Phil. Mag., 48, 474 (1899). Coagulating power of electrolytes, theoretical.

I21. H. C. Wood: Merck's Archiz., I, 374 ; also Pham. Kez., 17, 529 (I899). Colloidal silver in therapy.

122. Bredig: Ztschr. phys. Chem, 32, 127 (1900). Preparation of colloidal cadmium.

123. Bredig: Chem. Ztg, 24, 895 ( I900). Similarity of action of colloidal platinum and organic ferments.

I 24. Bredig: Phys. Ztschr., 2, 7 ( rgoo), Brief review of colloidal metal solutions.

125. Bredig and Coehn: Ztschr phys. Chem., 32, I29 (1900). Concerning colloids. Notes on researches of Messrs. Stoeckl, Vanino and Stark.

I26. Cohnheim: "Chemie der Erweisskorper," (I900). General discussion of coagulation of colloid solutions and adsorption of material from solt tion.

127. Duhem: J. Phys. Chem., 4, 65, 598 (1900). Emission and absorption of water-vapor by colloidal jellies.

I 28. Elster and Geitel: Revue Scientifique, 4, 13-472 ( 1900). Precipitation of rain and atmospheric electricity.

129. Goodwin and Grover: Phys. Rev., II, I93 (1900). Colloidal ferric hydroxide in ferric chloride solutions.

130. Guoy: Compt.rend., 131,939 (1900). Capillary electric phenomena and adsorbing power of surfaces.

I31. Hardy : Ztschr, phys. Chem, 33, 385 (1900). Colloid solutions; properties of gum mastix and egg albumen solutions.

I32. Hardy : Proc. Roy. Soc., 66, 95, 110 (1900). The dependence of the coagulation of colloidal solutions upon the nature of the ions of the electrolyte.

133. Harris: $J$ Physiol., 25, 207 (1900). Filtration of colloids from solution under pressure by means of membranes.

134. H. A. Lobry de Bruyn: Rec. trat. chim. pays-bas, 19, 236 (1900). Specific state of insoluble substances when formed in a mixture of gelatine. Such substances often remain in this case as colloidal solutions instead of coagulated precipitates.

135. Levi : Chem. Centrbl., 2, 658 (I900). Contribution to the study of substances in colloidal solutions.

136. Monton: Ann. Inst. Pastewr, 14, 571 ( I900). Practically a review of Bredig's work.

137. Pauli and Rona: Wien. Ber, 26, 283 (1900) ; Wied. Beibl., 25, 115 (IgOI). Coagulation of glutin solutions by mixed salt solutions. 
138. Smits : Versl. Kon. Akad. v. Wet. Amsterd.am, I12 (1900). Cryoscopic investigation and vapor-pressure of soap solutions.

139. Spring: Rec.trav. chim. pays-bas, 19, 204 (1900). Coagulation or flocculation of turbid solutions.

140. Stockl and Vanino: Zischr,phys. Chem., 34, 378 (1900). Colloidal gold solutions and Tyndall effect.

I4I. Van Bemmelen: Ztschr. anorg. Chem., 23, 32I (I900). Adsorption or absorption of substances from solutions by jellies and other insoluble finely divided material. Decomposition of neutral salts and absorption of base or acid.

142. van Bemmelen, J. M. : Ztschr. anorg. Chem, 23, II I (1900). Absorption of hydrochloric acid and potassium chloride from solutions by colloidal tin oxide.

I43. Zsigmondy, R. : Ztschr. phys. Chem., 33, 63 (rgoo). Remarks oll the nature of so-called colloidal metal solutions.

144. Bredig, O., and Ikeda, K. : Ztschr. phys. Chem., 37, i (1900). Catalytic action of colloidal platinum as effected by poisons.

I45. Bredig, G. : Ztschr. phys. Chem. 38, I22 (1901). Destruction of the catalytic action of colloids by poisons.

I46. Bredig and Reinders : Ztschr. phys. Chem., 37, 323 (Igor). Catalysis of hydrogen peroxide by colloidal gold and effects of some "poisons" on colloidal gold.

147. Donnan: Phil. Mag., (6), I, 647 (I9ot). Theory of colloidal solutions assuming heterogeneous mixtures.

I48. Erust, Carl : Ztschr. phys. Chem., 37, 448 ( I9or). Catalysis of electrolytic gas by colloidal platinum.

I49. Posternak: Ann. de l'Institut Pasteur, No. 2, 1901. Coagulation of colloidal albumenoids. Considers coagulation to be determined by the relation of undissociated to dissociated molecules of electrolytes.

MassachusetTs INSTITtTE OF TECHNOLOGY.

NOTE.

Reply to Dr. Ewell's "Notes on the Paper by Hiltner and Thatcher.-In an article recently published in this Journal, we outlined a modification of the Sachs-Le Docte modification of Pellet's "instantaneous aqueous diffusion methods for the estimation of the sugar content of beets." In the succeeding number of the Journal, Dr. E. E. Ewell published some notes on our paper ${ }^{1}$ criticizing the proposed modification in several points. Inasmuch as Dr. Ewell has apparently fallen into some of the errors which we specifically warned against in our previous article, it would seem that a further word of comment is necessary. This reply has been delayed by the withdrawal of $\mathrm{Mr}$. Thatcher from this laboratory and by the many distractions of the summer vacation season, but may not be out of place at this time.

1 This Journal, 23,432 . 